\title{
A simbólica utopia felina e o reconhecimento da razão animal em "Um sonho de mil gatos", de Neil Gaiman
}

\section{The symbolic feline utopia and the recognition of the animal reason in "A dream of a thousand cats", by Neil Gaiman}

\author{
Luciano Mendes Duarte Júnior ${ }^{1}$ \\ Marcus Vinícius Matias ${ }^{2}$
}

DOI: $10.28998 / 2317-9945.2019$ n63p306-318

\section{Resumo}

Graphic novel lançada entre 1989 e 1996, Sandman segue a jornada da personagem-titulo, governante do mundo dos sonhos e entidade que existe desde o início dos tempos. Em Um sonho de mil gatos (1990), Sandman adquire a forma de um felino. A bistória apresenta uma gata doméstica que busca mudar o mundo através dos sonhos. A partir disso, este trabalho tem como objetivo analisar os simbolos na narrativa e a construção utópica através do ato de sonhar. Para tanto, serão utilizados: Chevalier e Gheerbrant (2015), a fim de auxiliar na análise dos simbolos presentes na obra; Bloch (1995), para a discussão sobre sonhos como pensamento utópicos; e Jung (2016), para as reflexões sobre as concepções de sonbo enquanto simbolo. Por fim, através das leituras mencionadas, além da análise minuciosa da graphic novel em questão, nota-se que o sonhar conduz. o processo de construção do utópico apresentado na narrativa.

Palavras-chave: Gatos. Narrativa Gráfica. Simbolos. Sonbo. Utopia

\begin{abstract}
Graphic novel published between 1989 and 1996, Sandman follows the journey of the eponymous character, ruler of the dreaming world and entity who exists since the beginning of time. In A dream of a thousand cats (1990), Sandman becomes a cat. The story presents a domestic cat that intends to change the world through dreams. Taking this into account, this paper aims to analyze the symbols in the narrative and the utopic construction through the act of dreaming. To that end, the following will be used: Chevalier e Gheerbrant (2015), in order to support the analysis of the symbols present in the work; Bloch (1995), for the discussion on dreams as utopic thinking; and Jung (2016), for the reflections upon the conceptions of dream as a symbol. At last, through the aforementioned readings, in addition to the thorough analysis of the graphic novel under discussion, it can be noticed that the dreaming is what leads the process of the utopic construction presented in the narrative.
\end{abstract}

Keywords: Cats. Dream. Graphic Novel. Symbols. Utopia

Recebido em: 14/07/2018.

Aceito em: 16/07/2018.

\footnotetext{
${ }^{1}$ Mestrando em estudos literários pelo Programa de Pós-graduação em Letras da Universidade Federal de Minas Gerais. Graduado em Letras - Inglês pela Universidade Federal de Alagoas.

2 Professor adjunto da Universidade Federal de Alagoas e pesquisador na linha de Estudos Literários.
} 


\section{Introdução}

Os quadrinhos possuem uma linguagem distinta, numa dinâmica entre recursos escritos e visuais, afirmando-se enquanto um gênero diferenciado, portador de suas próprias especificidades. Esse gênero, embora pareça relativamente novo na maneira como o concebemos nos nossos dias, possui uma trajetória que acompanha a nossa própria História. Eisner (2005), ao discorrer sobre a história da narrativa, afirma que:

O ato de contar histórias está enraizado no comportamento social dos grupos humanos - antigos e modernos. As Histórias são usadas para ensinar o comportamento dentro da comunidade, discutir morais e valores, ou para satisfazer curiosidades. Elas dramatizam relações sociais e os problemas de convívio, propaga ideias ou extravasa fantasias. Contar uma história exige habilidade.

Antigamente, o contador de histórias de um clã ou uma tribo servia como anfitrião, professor e historiador. Contar histórias preservava o conhecimento passando-o de uma geração para outra. Essa missão continuou até os tempos modernos. O narrador tem, primeiro, que ter algo a dizer, e, então, ser capaz de manusear as ferramentas para relatar (EISNER, 2005, p. 11).

Assim, o ato de relatar histórias através de imagens está ligado às origens das primeiras comunidades humanas, que se utilizavam de gravuras (geralmente desenhadas nas paredes das cavernas) para registrar acontecimentos. Hoje, com o advento da impressão, a disseminação de charges, tiras, quadrinhos, etc. atende a diversos gostos, e essas mídias apresentam justaposições de imagem e escrita que, como afirma Eisner (2001, p. 8), ao falar sobre a leitura de quadrinhos, dão lugar a "um ato de percepção estética e de esforço intelectual".

Contudo, é importante deixar claro que a narrativa gráfica é mais do que apenas uma combinação de textos e imagens. Esse gênero requer um estilo de arte que consiste na maneira como as imagens relacionam-se com o texto escrito, como afirma Queiroz (2012. p. 44), quando diz que "Os traços e desenhos adotados se moldam ao tipo de história que se conta". Dito isso, é interessante destacar o pensamento de Eisner (2008, p. 159) de que "O estilo de arte não só conecta o leitor com o artista, mas também prepara para ambientação e tem valor de linguagem".

No que se refere a esse conceito de estilo de arte, analisar Sandman (1989-1996) consiste numa tarefa complexa, mas extremamente prazerosa. $\mathrm{O}$ tex to denso conduzido com maestria por Neil Gaiman e os traços de artistas célebres como Sam Kieth, Mike Dringenberg, Bill Sienkiewicz, Dave McKean e Matt Wagner misturam-se no emaranhado de simbolismos e referências à literatura, mitologia, fatos históricos, música e tantas outras esferas intertextuais que compõe o universo onírico da história do Rei dos Sonhos. Por isso, faz-se necessária a explicitação da perspectiva tomada nessa pesquisa, a fim de estabelecer uma delimitação da análise executada neste trabalho.

Por conseguinte, o presente estudo pretende identificar os elementos simbólicos presentes na narrativa, relacionar a figura do gato à figura do Sonho e, por fim, refletir sobre a construção do universo utópico através do ato de sonhar. Para tanto, na primeira parte deste artigo haverá uma breve apresentação da novela gráfica, seguida da descrição da história escolhida para análise que, por sua vez, precederá a discussão dos elementos simbólicos 
identificados na trama e como eles auxiliam na construção do universo utópico almejado pelos gatos - personagens centrais do enredo.

A seção seguinte tratará do caráter utópico dos sonhos e, logo mais, haverá uma breve análise da narrativa através da perspectiva da Jornada do Herói. Por fim, a conclusão discorrerá sobre os resultados obtidos através dos recursos simbólicos e como eles relacionam-se com a construção do utópico apresentado na narrativa. Concomitantemente, durante todo este trabalho, serão apresentadas também algumas observações técnicas da obra.

\section{Sandman: a série gráfica}

Criada por Neil Gaiman em resposta a um pedido da DC Comics, empresa americana de quadrinhos e mídias afins e que tinha como objetivo reformular um super-herói já presente no seu universo ficcional, Sandman foi publicada pela primeira vez entre janeiro de 1989 e março de 1996, com um total de 75 edições divididas em 13 arcos originais. Com histórias voltadas para o público adulto, a narrativa acompanha a jornada da personagemtítulo, governante do mundo dos sonhos (o Sonhar) que, após passar mais de 70 anos preso por um grupo de ocultistas, precisa lidar com as consequências da sua ausência no mundo que conhecemos.

Sandman é um dos Perpétuos, entidades irmãs que existem desde o início dos tempos, antecedendo até mesmo as divindades, e que são responsáveis pela coesão de todas as coisas, lugares e seres existentes. Os Perpétuos são as personificações de aspectos conhecidos do nosso universo, sendo eles: Sonho, Morte, Desejo, Desespero, Delírio, Destruição e Destino. Cada qual é responsável pelo conceito que representa, tendo essa responsabilidade como seu dever maior.

Embora o Sonho seja a personagem principal da narrativa, seus irmãos e irmãs vão sendo pouco a pouco apresentados/as e desenvolvidos/as em paralelo. Ao decorrer das edições, a obra constrói seu próprio universo onírico e apresenta diversas outras figuras de sua vasta mitologia, introduzindo personagens bíblicas, deuses, anjos, demônios, personalidades da cultura pop, etc.

Por mais que seja um ser que está além da nossa compreensão humana, Sonho apresenta traços comuns à humanidade, como solidão, culpa e melancolia. Ele está sempre refletindo sobre o sentido das coisas e de suas ações. Suas expressões e trejeitos são sempre soturnos e suas falas são representadas por balões pretos, de modo que refletem a personalidade da personagem, visto que, segundo Eisner (1989, p. 26), a configuração do balão é resultado "da personagem que fala".

Sandman, então, recebe diversas denominações e assume variadas formas no decurso da história (originalmente, é retratado com uma pele extremamente pálida e cabelos pretos bagunçados). Entre os nomes atribuídos a ele, temos: Sonho (dos Perpétuos), Morfeus, Rei dos Sonhos e do Reino dos Pesadelos, Lorde L'Zoril, Kai'ckul, Oneiros, Lorde Moldador, Príncipe das Histórias, Monarca das Fronteiras Adormecidas, entre outros. Por vezes, as distintas denominações correspondem a diferentes aparências. 


\section{A edição Um sonho de mil gatos}

Escrita por Neil Gaiman e tendo Kelley Jones, Malcolm Jones III e Robbie Busch como desenhista, arte-finalista e colorista, respectivamente, Um sonho de mil gatos (1990) mostra Sonho transmutado em um felino. O enredo apresenta personagens criadas pelo próprio Gaiman, Sam Kieth e Mike Dringenberg.

Essa edição faz parte do arco Terra dos sonhos (1990), que funciona como um intervalo entre os arcos Casa de bonecas (1989-1990) e Estação das brumas (1990-1991), apresentando tramas totalmente independentes entre si e da narrativa central de Sandman (1989-1996), como se fossem contos gráficos inseridos no meio da graphic novel.

Nessa história analisada, os gatos são antropomorfizados para agirem como personagens principais, mas isso acontece por intermédio da representação de suas capacidades de pensamento e fala apenas. Em relação a outros aspectos, eles são representados como gatos comuns, tais quais os conhecemos, respeitando seus traços físicos, aproximando a realidade do conto à nossa e, assim, acrescentando tons de realismo à leitura.

\section{A obra e seus símbolos}

Peirce (2015, p. 40) afirma que "todo símbolo é uma coisa viva, num sentido muito estrito que não é figura de retórica. O corpo de um símbolo transforma-se lentamente, mas seu significado cresce inevitavelmente, incorpora novos elementos e livra-se de elementos velhos". Dessa forma, o autor reconhece a vivacidade dos símbolos e como eles podem ser interpretados de diferentes formas. Assim, essa seção irá ocupar-se dessa interpretação simbólica, por meio de elementos presentes na narrativa em questão.

A história começa mostrando uma pequena gatinha branca que, ao ficar sozinha após seus donos terem ido para a cama, recebe a visita de um gato mais velho, convidando-a para um evento misterioso que ocorrerá naquela noite. O evento é, na verdade, um encontro com uma gata siamesa adulta que deseja compartilhar sua mensagem com seus colegas felinos. Ao chegarem no local de encontro (um cemitério), encontram vários outros gatos e, logo depois, a própria gata misteriosa, que se torna o centro da atenção de todos ali.

Assim, em um processo metanarrativo, a gata siamesa começa a contar sua história, alegando que já fora ingênua o suficiente a ponto de ser grata pela comodidade provida pelos humanos e de acreditar que tinha o controle sobre sua própria vida. Contudo, após se envolver com um gato de rua, ela teve filhotes mestiços que foram jogados em um rio por um de seus donos, visto que, na visão do humano, os gatinhos não valeriam nada.

Aqui, é interessante ressaltar que o clássico do gênero utópico, $A$ Utopia, aponta para a inadmissibilidade do maltrato aos animais em sociedades ideais, uma vez que os moradores da ilha descrita pelo viajante Rafael Hitlodeu "creem que o prazer de ver a morte, mesmo dos pequenos animais, demonstra os sentimentos de uma alma cruel, ou que surgiram pela prática contínua de tão terrível prazer” (MORE, 2017, p. 139). O ato descrito pela gata, então, revela a ausência de clemência no humano que condenou os filhotes à morte.

Foi a partir desse acontecimento que a gata se deu conta de sua subordinação perante os humanos e de que nunca seria realmente livre enquanto vivesse com eles. Logo após essa 
constatação, a gata rezou fervorosamente, a fim de receber justiça, revelação e sabedoria. A partir desse desejo, ela sonhou.

A gata havia acordado num deserto, lugar que, de acordo com Chevalier e Gheerbrant (2015, p. 331), simboliza uma busca, à semelhança da "busca dos hebreus da Terra Prometida através do deserto do Sinai, assim como a procura do Santo Graal". Além disso, ainda segundo os autores, o deserto é um ambiente "propício às revelações", que compunham precisamente um dos objetos de busca da gata.

Ademais, após ter sido abordada por um corvo com cabeça de ossos e de ter manifestado seus motivos para estar ali (a busca por justiça, revelação e sabedoria), a ave afirmara para a gata que revelação seria o único de seus anseios que poderia ser atendido naquele mundo. A figura do corvo, a propósito, é descrita por Chevalier e Gheerbrant (2015, p. 294) como desempenhando "o mesmo papel de mensageiro dos deuses e exercendo função profética". Essa última concepção pode, facilmente, ser associada à noção de "revelação". Além disso, na obra de Neil Gaiman, a figura do corvo é constantemente associada ao Sonho.

Foi a partir daquele momento, como relata a gata, que o corvo lhe deu os direcionamentos para que ela chegasse até o Gato dos Sonhos, descrito como o regente daquele mundo adormecido. A ave alertara, porém, que o caminho até a montanha, local no qual ele se encontrava, seria difícil e perigoso. Mas a gata, obstinada, não desistira de sua busca e subira a montanha.

A montanha, por sua vez, consoante Chevalier e Gheerbrant (2015, p. 616), "participa do simbolismo de transcendência" e é a "morada dos deuses e objetivo da ascensão humana". Faz-se necessário aqui, claro, para o estudo proposto neste trabalho, desenvolver as noções de "deuses" e "humano" para as concepções de "entidades" e de "animais", respectivamente, e que são representados, nesta mesma ordem, pelo Sonho e pela gata siamesa. A noção de "transcendência", por seu turno, será explorada na seção seguinte deste artigo, intitulada "A Jornada da Heroína", que descreve com mais detalhes o caminho percorrido pela felina, com base nas formulações propostas pelo antropólogo Joseph Campbell.

Ao chegar no topo da montanha, a gata depara-se com a caverna do Gato dos Sonhos. A caverna é o "arquétipo do útero materno, [...] figura nos mitos de origem, de renascimento e de iniciação de numerosos povos" (CHEVALIER; GHEERBRANT, 2015, p. 212). Desse modo, pode-se afirmar que a caverna representa o renascimento simbólico da gata siamesa, uma vez que, ao obter aquilo que tanto procura (sabedoria), sairá dali como uma nova felina, podendo esse ser considerado, então, seu rito de iniciação.

A entrada da caverna, contudo, é protegida pelos seus três guardiões: um grifo, um lagarto gigante e um pégaso. Cabe-se aqui uma exploração dos simbolismos dessas criaturas, visto que para os gregos, como escrevem Chevalier e Gheerbant (2015, p. 478; p. 533; p. 703), "os grifos são iguais aos monstros que guardam tesouros. [...] Simbolizam a força e a vigilância, mas também o obstáculo a superar para chegar ao tesouro". O lagarto, por sua vez, "simbolizaria [...] a alma que busca humildemente a luz", enquanto o pégaso, por fim, "representa a imaginação criadora" (grifo dos autores).

Após superar todos os obstáculos em seu caminho, a gata procura por um "tesouro": é o tesouro da sabedoria, concepção associada à ideia de "luz", uma vez que esta simboliza 
o conhecimento (CHEVALIER; GHEERBRANT, 2015). Essa luz, por conseguinte, como veremos mais adiante nesta análise, diz respeito à capacidade de "imaginação criadora" por parte da gata por meio de seus sonhos. Isso posto, pode-se notar como a aparição dessas criaturas enriquecem a narrativa, tendo em vista que seus simbolismos ajudam na constituição da atmosfera mítica da história.

Dentro da caverna, depois de convencer os guardiões a deixá-la entrar, a gata finalmente encontra o Gato dos Sonhos. Como já mencionado, Sonho pode assumir diversas formas. Na verdade, sua caracterização depende daqueles(as) a quem ele se apresenta. No caso de Um sonho de mil gatos (1990), por se tratar de uma história sobre felinos, é na forma de um gato que o Rei dos Sonhos surge.

A figura do gato, assim como todos os grandes símbolos, possui aspectos positivos e negativos. Carrega consigo as ideias de sabedoria superior e, se for preto, representa a obscuridade (CHEVALIER; GHEERBRANT, 2015). Sandman, enquanto Gato dos Sonhos, é o detentor da "sabedoria superior" procurada pela gata siamesa e a obscuridade é uma característica condizente com a sua personalidade.

Ainda, é importante mencionar que essa não é a primeira vez em que Sonho aparece como um felino. Na edição de estreia, O Sono dos Justos (1989), ele surge como gato ao libertarse de sua prisão que durara décadas. É na forma desse animal que ele vai atrás do atual responsável pelo seu encarceramento.

Assim, a narrativa explora o senso de justiça inerente aos animais, conforme as palavras de Montaigne, quando diz que: "Se, para sermos justos, devemos dar a cada um o que lhe é devido, diremos que os animais servem, amam, e defendem seus benfeitores; perseguem e agridem os estranhos e os que os ofendem, praticando uma justiça igual à nossa" (MONTAIGNE, 1984, p. 219).

Por seu turno, o aspecto simbólico explorado na obra-objeto desta pesquisa é o saber superior associado à figura do gato. O Gato dos Sonhos revelara que já houve um tempo em que eram os felinos que dominavam o mundo, sendo a humanidade a espécie que lhes servia de animal de estimação, recreação e, até mesmo, presa.

Tudo mudou quando um humano sonhou com um mundo diferente, no qual os da sua espécie eram os governantes. Depois disso, ele contou do seu sonho para os seus semelhantes e espalhou a palavra de que, se todos sonhassem com um mundo de humanos, tudo iria mudar e eles não mais seriam caçados e mortos pelos gatos, pois, segundo ele, os sonhos tinham o poder de moldar o mundo. Quando mil humanos sonharam o mesmo sonho, o mundo como conheciam mudou, e eles, agora, eram a espécie dominante.

Após ouvir esse relato, a gata soubera qual era sua missão: percorrer o mundo pedindo para que os da sua espécie sonhassem, a fim de reestabelecerem seu domínio. E é isso o que ela pede após contar a sua história para aqueles que foram ao cemitério escutá-la. Dessa forma, a gata assume uma função de messias/profeta entre os outros felinos. Esse seu papel é sugerido logo no momento no qual ela aparece pela primeira vez, como se vê na figura 1. 
Figura 1: fragmento de Sandman.

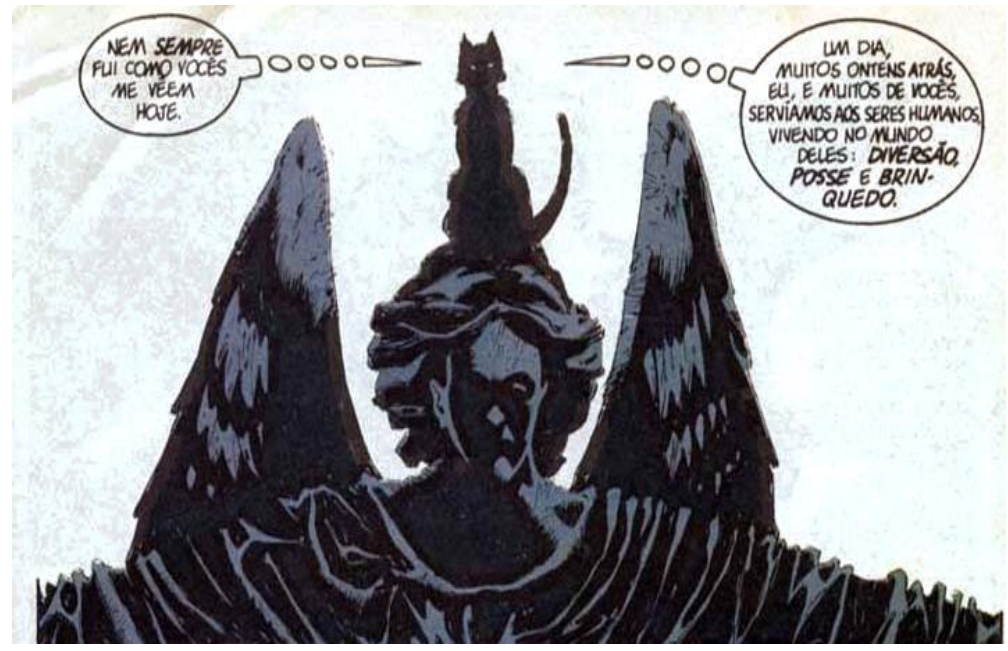

Fonte: Gaiman, 1990, p. 7.

Surgindo em cima da estátua de um anjo, a gata revela seu papel de salvadora de sua espécie. Esse pensamento torna-se ainda mais forte se levado em conta o fato de que o encontro acontece em um cemitério, simbolizando o declínio do domínio que os gatos um dia já tiveram e que agora está morto. Esse traço de discurso messiânico/profético também fica evidente quando a gata se refere às suas palavras como as "boas novas", termo de cunho bastante religioso.

Aquela que parece mais crente no que ouve é a gatinha branca apresentada no início da história. Em seu artigo sobre a obra, Exploring dream country: literary critique of Neil Gaiman's "Sandman", Willms (2018, s/p) escreve que o branco faz referência à "pureza, inocência e esperança. São essas as qualidades na gatinha que mostra à Siamesa que sua mensagem foi aceita sem o filtro cínico dos outros gatos"3. A autora ainda segue afirmando que é a juventude que costuma carregar o progresso e a mudança, e que assim também poderia ser naquela realidade, uma vez que os gatos mais velhos estão felizes com as coisas do jeito que são e são mais céticos em relação à história da gata siamesa.

Independentemente da idade, porém, todos os gatos precisam assumir para si o desejo de sonhar. A siamesa, por sua vez, leva sua palavra a todas as partes do mundo, e a todos os tipos de felinos, incluindo os solitários e ferozes. E assim, se um dia, mil gatos sonharem, o mundo será deles novamente. Aqui, destacam-se o desejo e o sonho como elementos principais que servem de motivadores da utopia.

\section{O caráter utópico dos sonhos}

Visto que a obra possui uma forte presença de símbolos, mostra-se indispensável explorar a noção de sonho como tal, uma vez que esse é o elemento simbólico mais forte da história, capaz até mesmo de mudar o mundo. Jung (2016) define o sonho como imagem simbólica e diz ainda que seu simbolismo "tem tanta energia psíquica que somos obrigados

\footnotetext{
${ }^{3}$ Tradução minha.
} 
a dar-lhe atenção" (2016, p. 56). É através de um sonho que a gata toma para a si seu papel profético. Sua energia psíquica lhe serve de motivação.

Bloch (1995), em seu livro intitulado O princípio esperança, também aborda os sonhos como símbolos, relacionando-os à esperança/intenção de uma vida melhor. O autor afirma que "O Não para a má situação que existe, o Sim para a vida melhor que paira à frente, são incorporados pelo desfavorecido ao interesse revolucionário" "(BLOCH, 1995, p. 75, grifo do autor). Então, o autor comenta sobre os sonhos diurnos e os descreve como sonhos de uma vida melhor, pois surgem de uma sensação de ausência que precisa ser interrompida. Ele também inclui nessa concepção os sonhos noturnos, que também dizem respeito a essa consciência utópica. Dessa forma, é plausível supor que o interesse revolucionário da siamesa é capaz de guiar a sua espécie até a utopia dos gatos.

A diferença que o autor estabelece entre sonho diurno e noturno é a predominância do inconsciente no segundo, enquanto que, no primeiro, o consciente mostra-se mais presente. $\mathrm{Na}$ obra aqui analisada, pode-se dizer que esses dois tipos de sonhos se relacionam, uma vez que os gatos precisam ter o desejo consciente de sonhar com um futuro melhor e, assim, alcançar o seu objetivo através do sonho noturno, capaz de reformular o mundo.

Para o autor, "O desejo de viajar até o fim no qual tudo termina bem sempre permeia a consciência utópica, desempenha essa consciência com um espírito de conto de fadas a nunca ser esquecido, trabalha nos sonhos de uma vida melhor [...]" (BLOCH, 1995, p. 98). Os sonhos diurnos abrem janelas através das quais o objetivo utópico pode ser alcançado, mantendo a esperança viva (BLOCH, 1995). Esse tipo de sonho almeja sempre a concretização de seus desejos, como identificado nas palavras e atitudes da gata siamesa.

\section{A Jornada da Heroína}

Um sonho de mil gatos (1990) apresenta ainda evidências da esquematização da "Jornada do Herói", termo criado por Joseph Campbell em 1949, no seu livro intitulado O herói de mil faces, e que também é conhecido como "monomito". Essa noção, contudo, não é nova. Histórias como as de Jesus Cristo e Osíris já apresentavam essa estrutura. Após reconhecêla, Campbell a sistematizou em três estágios: A Partida (A aspiração do herói à aventura), A Iniciação (Os desafios que encontra pelo caminho) e O Retorno (A volta para casa com os conhecimentos e/ou poderes adquiridos).

Cada um desses três estágios é dividido em subseções. São elas: 1) O chamado da aventura, 2) A recusa do chamado, 3) $\mathrm{O}$ auxílio sobrenatural, 4) A passagem pelo primeiro limiar, 5) $\mathrm{O}$ ventre da baleia, 6) $\mathrm{O}$ caminho de provas, 7) $\mathrm{O}$ encontro com a deusa, 8) A mulher como tentação, 9) A sintonia com o pai, 10) A apoteose, 11) A bênção última, 12) A recusa do retorno, 13) A fuga mágica, 14) O resgate com auxílio externo, 15) A passagem pelo limiar do retorno, 16) Senhor dos dois mundos e 17) Liberdade para viver. Assim, os itens 1-5 correspondem ao estágio A Partida, enquanto as seções 6-11 e 12-17 dizem respeito aos estágios A Iniciação e O Retorno, respectivamente.

É importante destacar que nem todas as narrativas que se utilizam da noção da Jornada do Herói exploram a totalidade dos componentes dessa estrutura. Às vezes, algumas

\footnotetext{
${ }^{4}$ Todas as traduções de Bloch (1995) presentes neste trabalho são de minha autoria.
} 
partes ficam apenas subentendidas ou são até mesmo deixadas de lado. A estrutura tríade principal, contudo, continua presente. $\mathrm{Na}$ obra analisada neste artigo, por exemplo, temos a presença de apenas algumas das subseções mencionadas. Todavia, essa omissão da estrutura completa não afasta a história do conceito de monomito, pois os três estágios basilares se mantêm consistentes e reconhecíveis.

O primeiro aspecto da estrutura da Jornada do Herói na obra é "o chamado da aventura”, no qual a gata siamesa, após ter seus filhos friamente jogados em um rio para morrerem, dá-se conta da sua subordinação perante a humanidade. Sua negação ao estado atual das coisas desperta em si um desejo crescente por justiça, sabedoria e revelação, podendo esse ser considerado o seu momento de despertar para a jornada, pois, assim como afirma Campbell (1989, p. 35), os exemplos de como uma aventura se inicia "podem ser multiplicados, ad infinitum, vindos de todos os cantos do planeta" (grifo do autor).

Esse processo de iniciação desencadeia mudanças significativas na personalidade do herói, visto que, ainda segundo Campbell (1989, p. 31), esse chamado indica que "O horizonte familiar da vida foi ultrapassado; os velhos conceitos, ideias e padrões emocionais, já não são adequados; está próximo o momento da passagem por um limiar”. Esse pode, inclusive, ser considerado o segundo momento do monomito presente na obra: o momento da "passagem pelo primeiro limiar". Campbell (1989) complementa suas considerações sobre "o chamado da aventura" dizendo que:

Esse primeiro estágio da jornada mitológica — que denominamos aqui “o chamado da aventura" - significa que o destino convocou o herói e transferiu-lhe o centro de gravidade do seio da sociedade para uma região desconhecida. Essa fatídica região dos tesouros e dos perigos pode ser representada sob várias formas: como uma terra distante, uma floresta, um reino subterrâneo, a parte inferior das ondas, a parte superior do céu, uma ilha secreta, o topo de uma elevada montanha ou um profundo estado onírico (CAMPBELL, 1989, p. 34).

$\mathrm{Na}$ história, essa "região desconhecida" é representada pelo "profundo estado onírico" da gata siamesa, visto que é através do sonho que ela acaba adentrando o reino de Sandman, "uma terra distante". Ao encontrar-se no Sonhar, a gata se depara com o "guardião do limiar", representado pelo corvo morto. A ave descreve o caminho que deve ser seguido pela felina até o Gato dos Sonhos e é a partir daí que temos mais outro elemento da esquematização proposta por Campbell: "O caminho de provas", o primeiro do estágio denominado A Iniciação. Campbell (1989) diz que:

Tendo cruzado o limiar, o herói caminha por uma paisagem onírica povoada por formas curiosamente fluidas e ambíguas, na qual deve sobreviver a uma sucessão de provas. Essa é a fase favorita do mitoaventura. Ela produziu uma literatura mundial plena de testes e provações miraculosos (CAMPBELL, 1989, p. 57).

Essa “sucessão de provas" está presente na procura da felina pelo Gato dos Sonhos através do Sonhar e associada ao simbolismo da montanha, se também levarmos em conta que, para os povos africanos, a montanha "É um dos lugares onde reside o sagrado: não se pode nele penetrar sem um guia (o iniciador), sob pena de perigos mortais: símbolo do desejo de iniciação, ao mesmo tempo que das suas dificuldades" (CHEVALIER; GHEERBRANT, 2015, p. 619). Essas dificuldades enfrentadas pela gata durante a subida da montanha são mostradas nas figuras 2 e 3 : 
Figura 2: fragmento de Sandman.
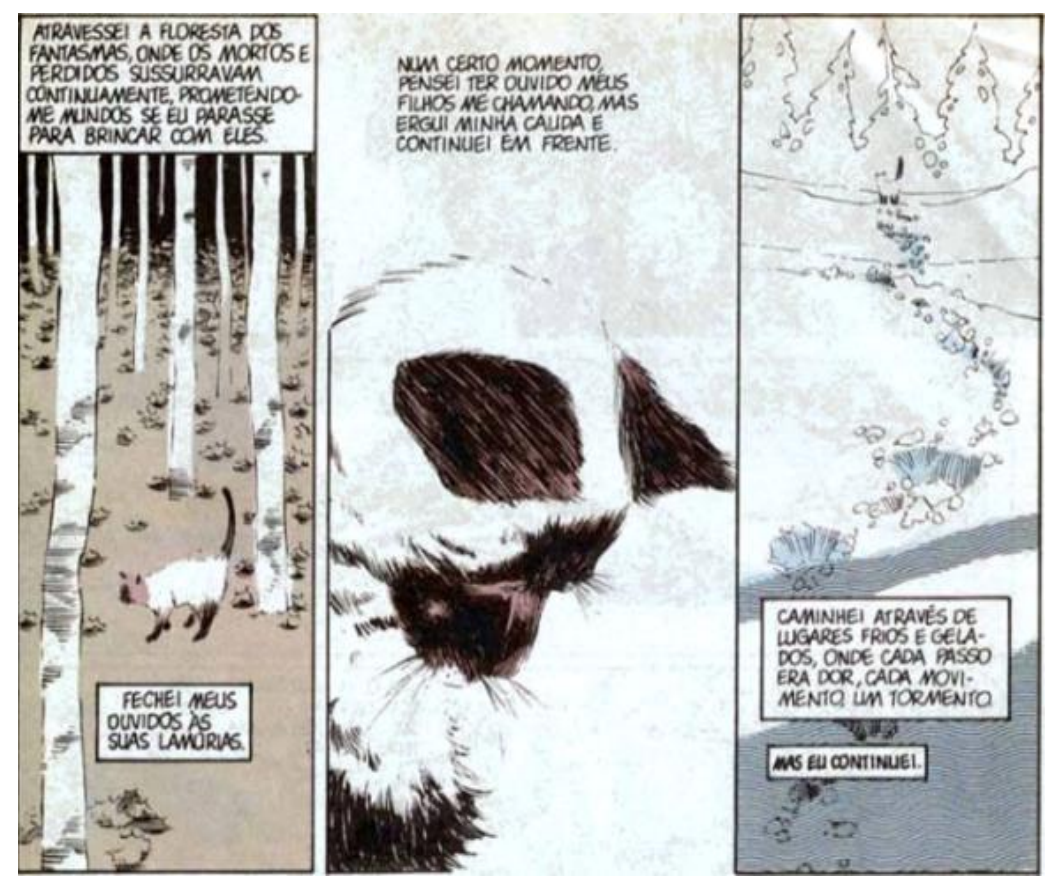

Fonte: Gaiman, 1990, p. 12.

Figura 3: fragmento de Sandman.

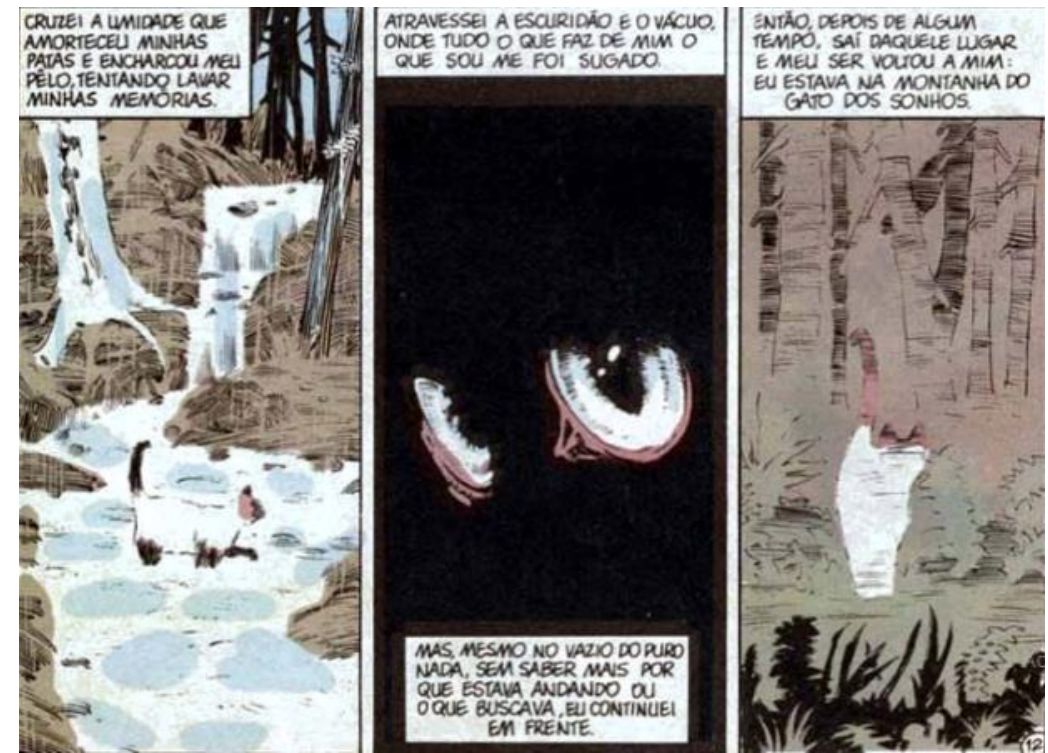

Fonte: Gaiman, 1990, p. 12.

Para a descrição da jornada da gata, é usado um amontoamento de quadrinhos estreitos com tamanhos quase iguais. Esse recurso, nas palavras de Eisner (1989), serve para conferir o aceleramento do ritmo da leitura, desenvolvendo uma narração ininterrupta. De acordo com o autor, "Nas modernas tiras ou revistas de quadrinhos, o recurso fundamental para a transmissão do timing é o quadrinho" (EISNER, 1989, p. 28). Timing, por sua vez, é descrito por Eisner como "o uso dos elementos do tempo para a obtenção de uma mensagem ou emoção específica” (EISNER, 1989, p. 26), elementos esses que incluem, além de outros 
meios, o quadrinho e o balão. O timing, então, a partir dos quadros mencionados, indica a dificuldade da busca da gata.

A gata penetrara na Floresta dos Fantasmas, na qual os mortos e perdidos - e até mesmo seus filhotes mortos - pediam para que ela parasse para brincar com eles; cruzara lugares frios e gelados, lidando com as dores de cada passo e movimento; atravessara lugares úmidos que a encharcavam e tentavam lavar suas memórias; e, por fim, percorrera a escuridão e o vácuo, esquecendo-se de quem era e do porquê estava ali. Contudo, graças à sua determinação, a gata conseguira superar todos os desafios e chegar até o cume da montanha.

Então, após enfrentar os desafios do caminho, lidar com os guardiões da caverna e de deparar-se com o Gato dos Sonhos, tem-se a fase intitulada "A benção última", na qual a figura heroica busca pelo poder da substância sustentadora dos deuses (aqui representados por Sandman zoomorfizado em Gato dos Sonhos). Segundo Campbell (1989, p. 96), "Essa miraculosa energia, e só ela, é o Imperecível".

Assim, ao fim desse processo de iniciação, "a mente quebra a esfera limitadora do cosmo e alcança uma percepção que transcende todas as experiências da forma - todos os simbolismos, todas as divindades: a percepção do vazio inelutável" (CAMPBELL, 1989, p. 101). Esse caráter de transcendência é representado, na obra, pela obtenção por parte da gata do conhecimento compartilhado por Sandman.

O último estágio, O Retorno, é o que possui menos representação em Um sonho de mil gatos (1990), mas isso se deve, contudo, ao caráter inacabado do conto gráfico, visto que o desejo de que mil gatos sonhem a mesma coisa ainda não fora alcançado. Apesar disso, pode-se destacar a fase "Senhor dos dois mundos", na qual, após adquirir recompensas do local percorrido, o herói volta para o seu mundo com o conhecimento dos dois domínios.

Nesse momento, o herói abraça suas responsabilidades provenientes dos conhecimentos e/ou habilidades adquiridos e renuncia a suas questões pessoais. Nessa fase, como descreve Campbell (1989, p. 132), "Suas ambições pessoais estão dissolvidas, razão por que ele já não tenta viver, mas simplesmente relaxa diante de tudo o que venha a se passar nele; ele se torna, por assim dizer, um anônimo. A Lei vive nele com seu próprio consentimento irrestrito". Na obra, a gata recebe a missão de disseminar entre seus colegas felinos a "Lei" que diz respeito ao renascer do domínio destes, renunciando a si própria em prol do bem coletivo.

\section{Considerações finais}

Ao dedicar uma história aos gatos, Neil Gaiman apresenta uma narrativa com ares de conto de fadas e de fábula e expande o alcance da influência do Sonho a outros animais que não os antropomórficos. Dessa forma, a capacidade dos animais de sonhar e, consequentemente, de raciocinar é reconhecida dentro do universo de Sandman (1989-1996), no qual os gatos tomam os papéis de protagonistas.

Além disso, ao sonhar com um mundo diferente, a humanidade reescreveu a própria história, de modo que o mundo dominado pelos gatos nunca existiu. A realidade na qual a humanidade é soberana, então, é descrita como existente desde sempre. Isso nos remete a 
discursos conservadores que, em razão da manutenção do tradicional, tentam estabelecer concepções imutáveis e inquestionáveis, na qual a mudança no status quo é impraticável e as classes oprimidas devem aceitar seu lugar de inferioridade, conformando-se com seu estado de sujeição.

A siamesa toma para si a tarefa de espalhar entre os outros gatos - as figuras oprimidas - um pensamento revolucionário, almejando um lugar melhor para todos eles. $\mathrm{O}$ sonho compartilhado representa a esperança coletiva de um determinado grupo que possui um ideal em comum. Entretanto, como pôde-se notar, o universo utópico almejado pelos gatos apresenta uma inversão dos papéis do universo já existente, no qual os gatos, antes oprimidos, subjugam a humanidade como abuso de seus poderes enquanto raça dominante. Vendo dessa forma, é plausível destacar que a utopia de uma espécie representa a distopia da outra.

Por fim, as discussões sobre sonhos enquanto símbolos apontam para como essas representações do (in)consciente podem ser analisadas enquanto construções utópicas. Os gatos usam essas imagens simbólicas como mecanismos de transformação do meio, partindo do princípio de que os sonhos são capazes de mudar o mundo. Assim, carregados com os desejos, anseios e esperanças dos gatos, os sonhos são a representação máxima da busca pelo não-lugar felino.

\section{Referências}

BLOCH, Ernest. The principle of hope: volume one. USA: The MIT Press, 1995.

CAMPBELL, Joseph. O herói de mil faces. Tradução: Adail Ubirajara Sobral. São Paulo: Editora Pensamento, 1989.

CHEVALIER, Jean; GHEERBRANT, Alain. Dicionário dos símbolos (mitos, sonhos, costumes, gestos, formas, figuras, cores, números). 28. ed. Rio de Janeiro: José Olympio, 2015 .

EISNER, Will. Quadrinhos e arte sequencial. São Paulo: Martins Fontes, 1989.

EISNER, Will. Narrativas gráficas. 2. ed. São Paulo: Devir, 2008.

GAIMAN, Neil. Um sonho de mil gatos. In: GAIMAN, Neil. Sandman. Porto Alegre: Editora Globo, 1990.

JUNG, Carl G. O homem e seus símbolos. 3. ed. Tradução: Maria Lúcia Pinho. Rio de Janeiro: HarperCollins Brasil, 2016.

MONTAIGNE, Michel Eyquem de. Ensaios. 3. ed. Tradução: Sérgio Milliet. São Paulo: Abril Cultural, 1984.

MORE, Thomas. A Utopia. Tradução: Márcio Meirelles Gouvêa Júnior. Belo Horizonte: Autêntica Editora, 2017. 
PEIRCE, Charles Sanders. Semiótica. Tradução: José Teixeira Coelho Neto. São Paulo: Perspectiva, 2015.

QUEIROZ, Jozefh Fernando Soares. Humor em quadrinhos: um estudo de narrativas gráficas brasileiras e argentinas. 2012. Dissertação (Mestrado em Letras e Linguística) Universidade Federal de Alagoas, Maceió, 2012.

WILLMS, Kristen. Exploring dream country: literary critique of Neil Gaiman's "Sandman". Disponível em: https://hobbylark.com/fandoms/Exploring-Dream-CountryLiterary-Critique-of-Neil-Gaimans-Sandman. Acesso em: 10 set. 2018. 